\title{
Visual sensitivity fluctuations during the menstrual cycle under dark and light adaptation
}

\author{
DENA SCHER \\ Margrove College, Detroit, Michigan 48221 \\ and \\ MARY PIONK and DEAN G. PURCELL \\ Oakland University, Rochester, Michigan 48063
}

\begin{abstract}
Highly trained subjects completed 500 trials under a signal detection rating scale procedure that tested visual sensitivity at five phases of the menstrual cycle under light and dark adaptation. Sensitivity was reliably increased at ovulation under dark adaptation. In contrast with this, light-adapted sensitivity did not change with phase. Previous research has not shown this pattern of result.
\end{abstract}

The effects of phase of the menstrual cycle on visual sensitivity to a briefly flashed stimulus has been assessed in two studies. Diamond, Diamond, and Mast (1972) employed the method of adjustment and found that dark-adapted sensitivity for a spot of light was lowest at menstruation and increased throughout the cycle, with the highest sensitivity occurring at ovulation through premenstruation. Ward, Stone, and Sandman (1977) employed a yes-no decision task with confidence ratings and found essentially the opposite pattern, with darkadapted sensitivity to a black dot being lowest premenstrually. The present study was designed to further investigate cyclic changes in visual sensitivity. A confidence rating signal detection technique was used to determine $\mathrm{d}_{\mathrm{e}}$ (Pollack \& Decker, 1958) at what were estimated to be the follicular, ovulatory, luteal, premenstrual, and menstrual phases. Neither Diamond et al. (1972) nor Ward et al. (1977) tested specifically at ovulation. In addition, both light- and dark-adapted sensitivity were studied.

\section{METHOD}

\section{Subjects}

Data were collected on four female students aged 1830 years. All subjects were paid, had normal visual acuity, and reported regular menstrual cycles of 26-29 days. None of the subjects was taking prescription medications. All four subjects completed light-adapted testing, and three completed darkadapted testing.

\section{Procedure}

Visual sensitivity ( $\left.\mathrm{d}_{\mathrm{e}} \mathrm{e}\right)$ under both dark and light adaptation was assessed periodically during the menstrual cycle. The subjects were tested during five phases of the menstrual cycle. The five phases were chosen so as to coincide with theoretical hormonal changes reported in the literature (Ross \& Vande Wiele, 1974). These were as follows: menstrual phase (Days 1-5), follicular phase (Days 6-13), ovulatory phase (Days 14-15), luteal phase (Days 17-21), premenstrual phase (1-3 days before the onset of menstruation). Each female with a 28-day cycle was tested on approximately the $1 \mathrm{st}, 7 \mathrm{th}, 14 \mathrm{th}, 21 \mathrm{st}$, and 28 th day of her cycle. Phase sequences were adjusted for shorter or longer cycles by testing at the $25 \%, 50 \%$, and $75 \%$ point in the cycle, with the 1st day of menstruation as the initial point. Subjects were tested at approximately the same time of day and were initiated into the test program on a different phase day.

During preexperimental sessions, the method of limits was used to obtain a duration threshold for each subject, with separate thresholds determined for dark and light conditions. These thresholds were then employed with the signal detection task.

One week prior to the first test session, subjects participated in two 2-h sessions to insure familiarization with testing procedures, provide practice, and minimize possible motivation effects. There were 1,000 practice trials for each subject under both light and dark adaptation.

During the experimental sessions under dark adaptation, each subject was seated in a dark testing room. Following $10 \mathrm{~min}$ of dark adaptation, each subject completed 100 practice trials and then 500 test trials. Signal and noise trials were randomly distributed and had equal probability of occurrence. The subject was asked to indicate if she saw a flash of light and to rate her confidence in each response (see Pollack \& Decker, 1958). A 5-min rest period was given halfway through the test trials. The experimental sessions under light adaptation were the same as those under the dark condition, except that subjects were tested in a normally lit testing room with stimuli exposed against a bright background. Light- and dark-adapted sessions were conducted in separate menstrual cycles.

\section{Apparatus}

An Iconix four-channel tachistoscope was used to present stimuli. Under dark adaptation, a .20-deg-diam .164-cd $/ \mathrm{m}^{2}$ target signal was located $.40 \mathrm{deg}$ above a .06-deg dim red fixation point. Under light adaptation, the target was exposed at $24.12 \mathrm{~cd} / \mathrm{m}^{2}$ and was superimposed upon a 3-deg-square $75.38-\mathrm{cd} / \mathrm{m}^{2}$ fixation field. This field was continuously exposed and contained a dark-on-light .66-deg fixation circle. The target was centered within this circle. The strip width of the circle was .06 deg. Luminance was controlled by Kodak wratten neutral density filters. Viewing was monoptic, under both light and dark conditions, with the subjects' reported eye of greatest acuity. 
Table 1

Average $\mathrm{d}^{\prime}{ }_{\mathrm{e}}$ and ROC Slope Under Dark Adaptation

\begin{tabular}{lrrrrr} 
& $\begin{array}{c}\text { Menstru- } \\
\text { ation }\end{array}$ & $\begin{array}{c}\text { Follic- } \\
\text { ular }\end{array}$ & $\begin{array}{c}\text { Ovula- } \\
\text { tion }\end{array}$ & Luteal & $\begin{array}{c}\text { Premen- } \\
\text { struation }\end{array}$ \\
\hline $\mathrm{d}_{\mathrm{e}}^{\prime}$ & 1.34 & 1.35 & 2.29 & 1.62 & 1.75 \\
Slope & .93 & .80 & .49 & .79 & .75 \\
\hline
\end{tabular}

Note-Premenstruation entries are based on data from two subjects.

\section{RESULTS}

ROC curves were fitted by eye to the points generated by the subjects' multiple criteria under the signal detection rating procedure. The slopes of the ROC curves on normal-normal paper varied from subject to subject and ranged from 1.00 to .38 . To insure comparability of data, the hit and false alarm rates at the point at which the negative diagonal intersected the ROC curve was used to calculate $d^{\prime}{ }_{e}$ (Green \& Swets, 1966). A significant effect of phase of menstrual cycle was obtained for the dark-adapted condition $[F(3,6)=9.33$, $\mathrm{p}<.025]$, but not for the light-adapted condition $[F(4,12)=.97]$. Note that premenstrual phase was not included in the analysis for the dark-adapted condition, as one subject did not complete this session. In the dark-adapted condition, the most pronounced effect was the increase in sensitivity at ovulation (see Table 1). In addition, for all subjects, the ROC for ovulation had the least slope $[F(3,6)=25.25, p<.005]$. This is consistent with other findings that the ROC slope decreases as $\mathrm{d}^{\prime}$ increases (Green \& Swets, 1966). However, slope changes usually result from changes in the stimulus, rather than changes in the observer. There were no indications of consistent slope differences in the lightadapted condition. There were no indications of consistent changes in criterion under light or dark adaptation. It was anticipated that there would be no effect of phase on criterion because of the extensive practice that subjects had received prior to data collection.

\section{DISCUSSION}

The present results indicate relatively stable dark-adapted visual sensitivity throughout the menstrual cycle, with the exception of an increase in sensitivity at ovulation. Two other studies also show an increase in sensitivity at ovulation. Barris, Dawson, and Theiss (1978) found an increase in scotopic sensitivity at ovulation by testing the 7 consecutive days in the middle of the menstrual cycle. Wong and Tong (1974) found sensitivity, for a two-flash threshold task, to be highest at ovulation. However, they found a more complex pattern of variation throughout the cycle than did the present study. The results of the light-adapted condition indicate that the effects found under dark adaptation may not generalize to the level of light adaptation used in the present study. The difference between light and dark adaptation suggests a limitation on a general arousal hypothesis of cyclical changes in visual sensitivity (Kopell, Lunde, Clayton, \& Moos, 1969), as well as on the idea that sensitivity changes occur so as to increase the probability of copulation at ovulation (Diamond et al., 1972). In their present form, neither of these hypotheses predicts a difference between light- and dark-adapted states. The present findings also indicate that care should be taken to determine the slope of the ROC curve to insure valid estimates of $d^{\prime}$ and criterion, as slope may well be a function of cycle phase.

\section{REFERENCES}

Barris, M. D., Dawson, W. W., \& Theiss, C. L. Human scotopic sensitivity increases on the day of ovulation. Supplement to Investigative Ophthalmology and Visual Science, 1978, $17,154$.

Diamond, M., Diamond, A. L., \& Mast, M. Visual sensitivity and sexual arousal during the menstrual cycle. Journal of Nervous and Mental Disease, 1972, 155, 170-175.

Green, D. M., \& Swets, J. A. Signal detection theory and psychophysics. New York: Wiley, 1966.

Kopell, B. S., Lunde, D. L., Clayton, R. B., \& Moos, R. H. Variations in some measures of arousal during the menstrual cycle. Journal of Nervous and Mental Disease, 1969, 148, 180-187.

Pollack, I., \& Decker, L. R. Confidence ratings and message reception for filtered speech. Journal of the Acoustical Society of America, 1958, 30, 432-434.

Ross, G. T., \& Vande Wiele, R. L. The ovaries. In R. H. Williams (Ed.), Textbook of endocrinology (5th ed.). Philadelphia: Saunders, 1974.

Ward, M. M., Stone, S. C., \& Sandman, C. A. Visual perception in women during the menstrual cycle. Physiology \& Behavior, 1977, 20, 239-243.

Wong, S., \& Tong, J. E. Menstrual cycle and contraceptive hormonal effects of temporal discrimination. Perceptual and Motor Skills, 1974, 39, 103-108.

(Received for publication July 9, 1981.) 